\title{
Won Do Heo
}

\section{Growing up curious in the countryside leads to tools for manipulating endogenous proteins.}

\section{I/ ood ideas come to me when \\ I am very comfortable, when
I am very happy," says Won}

Do Heo, who is on the biology faculty at

Korea Advanced Institute of Science and Technology (KAIST), and is a neuroscience fellow at the Institute for Basic Science, both in Daejon, Republic of Korea. An idea might come to him in a lab conversation, at a seminar or conference, when he is jogging, on one of his daily walks on a hill, or in the sauna at home.

It was a Korean national holiday and Heo was alone in the lab, thinking. He had spent a decade developing and using optogenetic tools. Suddenly, he realized how he might finally turn intrabodies, which are antibodies used to study intracellular proteins, into inducible tools.

Heo and his lab converted the idea into two classes of tools to target and manipulate proteins inside cells: optobodies, which can be activated by light; and chemobodies, which can be activated by small molecules. These tools leverage nanobodies, based on camelid antibodies, that are prized in cell biology for being soluble and small - they're around half the size of a green fluorescent protein molecule.

During that holiday musing, Heo had figured out at which cysteine residues he could split the nanobody to generate two inactive parts that do not bind a targeted protein. He checked the nanobody structure, and experiments got underway. The split structure lets an experimenter use light to, for example, activate or inhibit a protein at the cell membrane, at an organelle or in the cell nucleus. When the nanobody halves are separate, it's like having only one chopstick for a meal, he says. Work only gets done when the other half enters the scene.

The tools offer high-resolution temporal and spatial information about endogenous proteins, says Heo. With optobodies, light can help with manipulating a targeted protein and thus shape cell function. The team's chemobody would be good for an in vivo experiment, he says. Such studies, for example in neurobiology, are on his to-do list.

The lab used blue light to activate the optobody, but Heo believes he can get the tools to work with infrared light,

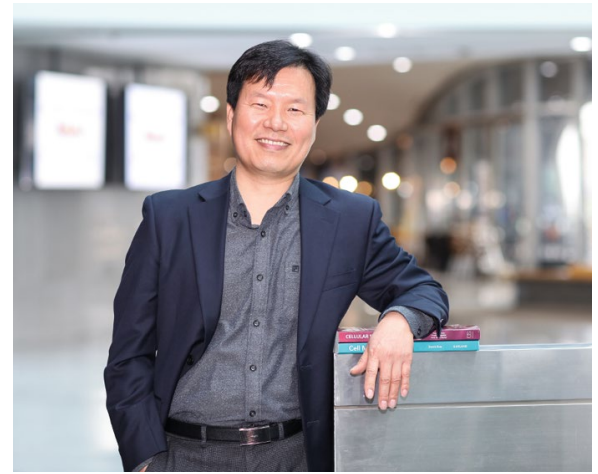

Won Do Heo.

too. Although there are many types of nanobodies, he believes the tools will work across this antibody class and for many types of questions. The chosen split site is in the antibody's highly conserved domain.

In his lab, says Heo, tool development involves intense testing, which takes a collaborative lab culture. Lab members not involved in a project are a tool's first users. This arrangement is not easy given his students' eagerness to publish quickly. But Heo seeks generalizable, broadly applicable tools. "I don't make very special, very tricky things," he says, which might only work in a few labs.

In his lab, Heo encourages his students to explore projects that intrigue them and that will make them happy during their years in his lab. "If they are not happy with something, I won't be happy, too."

Heo grew up on a farm in the country. "I didn't really have the plan to be a professor-researcher at the time," he says. He played with his dog, rabbit and cows, and was curious about how they interacted and cared for their young. He learned about rice and barley farming. "It's not textbook, it's just nature," he says. In high school, he began breeding birds: peacocks, turkeys, pheasants, parrots and canaries.

Even college was not in his plans, but curiosity led him to Gyeongsang National University. "I realized that I had to step up to another level," he says. Heo studied plant biology and switched to biochemistry in graduate school.

For his postdoctoral fellowship, curiosity was again a driver. He wanted to work in mammalian systems, and joined the Duke University lab of Tobias Meyer. Heo followed Meyer to Stanford University where, after a few years, he was promoted to staff researcher. After nine years in California, Heo joined KAIST and chose to focus on optogenetics.

Heo feels he can now combine his experience across fields: plant biology, cell biology, cell signaling and neurobiology. As Heo completed his $\mathrm{PhD}$, he remembers realizing that many plant proteins are not present in mammals, which might make them useful tools, he says. This idea has emerged as a cornerstone of optogenetics.

Optogenetics has taken cell biology labs beyond observation, which might miss half of the actual cellular events. Cells "are talking to each other, communicating to each other," he says. The ability to activate or deactivate proteins with light gives labs a way to explore cell biology more deeply and can help them, for example, determine proteins crucial to the cell cycle.

\section{"If they are not happy with something, I won't be happy."}

"I admire Won Do's work for its creativity; he has applied optical control by the cryptochrome-CIB1 interaction in very imaginative ways," says Heo's friend and colleague, Stanford University researcher Michael Lin. Heo and his students don't shy away from the hard work necessary to realize their ideas, says Lin. "Developing truly new methods is high-risk and timeconsuming, but Won Do has shown that the high rewards make it worth it."

Vivien Marx

Published online: 16 October 2019 https://doi.org/10.1038/s41592-019-0626-1

Reference

$\mathrm{Yu}$, D. et al. Optogenetic activation of intracellular antibodies for direct modulation of endogenous proteins. Nat. Methods https://doi.org/10.1038/ s41592-019-0592-7 (2019). 